\title{
Chrysanthemum zawadskii extract protects osteoblastic cells from highly reducing sugar-induced oxidative damage
}

\author{
KWANG SIK SUH ${ }^{1 *}$, SANG YOUL RHEE ${ }^{2 *}$, WOON WON JUNG ${ }^{3}$, NAM JAE KIM ${ }^{4}$, YOUNG PYO JANG ${ }^{5}$, \\ HYE JIN KIM ${ }^{5}$, MIN KYOUNG KIM ${ }^{5}$, YOUNG KIL CHOI ${ }^{6}$ and YOUNG SEOL KIM ${ }^{2}$ \\ ${ }^{1}$ Research Institute of Endocrinology, Kyung Hee University Hospital, Dongdaemun-gu, Seoul 130-702; \\ ${ }^{2}$ Department of Endocrinology and Metabolism, School of Medicine, Kyung Hee University, Dongdaemun-gu, \\ Seoul 130-701; ${ }^{3}$ Department of Biomedical Science, College of Health Sciences, Cheongju University, \\ Sangdang-gu, Cheongju, Chungbuk 360-764; ${ }^{4}$ East-West Medical Research Institute, Kyung Hee University Hospital, \\ Dongdaemun-gu, Seoul 130-702; ${ }^{5}$ Department of Oriental Pharmaceutical Science, College of Pharmacy, \\ Kyung Hee University, Dongdaemun-gu, Seoul 130-701; ${ }^{6}$ Department of Endocrinology and Metabolism, \\ Kangnam Cha Hospital, Kangnam-gu, Seoul 135-913, Republic of Korea
}

Received February 26, 2013; Accepted May 1, 2013

DOI: $10.3892 /$ ijmm.2013.1371

\begin{abstract}
In this study, Chrysanthemum zawadskii extract (CZE) was investigated to determine its effects on 2-deoxyD-ribose (dRib)-induced oxidative damage and cellular dysfunction in the MC3T3-E1 mouse osteoblastic cell line. Osteoblastic cells were treated with the highly reducing sugar, dRib, in the presence or absence of CZE. Cell viability, apoptosis and reactive oxygen species (ROS) production were subsequently examined. It was observed that $\mathrm{dRib}$ reduced cell survival, while it markedly increased the intracellular levels of ROS and apoptosis. However, pre-treatment of the cells with CZE attenuated all the dRib-induced effects. The antioxidant, $N$-acetyl- $L$-cysteine (NAC), also prevented dRibinduced oxidative cell damage. In addition, treatment with CZE resulted in a significant increase in alkaline phosphatase (ALP) activity and collagen content, as well as in the expression of genes associated with osteoblast differentiation [ALP, collagen, osteopontin (OPN), osteoprotegerin (OPG), bone sialoprotein (BSP), osteocalcin (OC) and bone morphogenetic protein (BMP)2, BMP4 and BMP7]. In mechanistic studies of the antioxidative potential of $\mathrm{CZE}$, we found that $\mathrm{CZE}$ reversed the dRib-induced decrease in the expression of phosphatidylinositol 3-kinase (PI3K) and protein kinase B (AKT)1 and AKT2 genes, which are master regulators of survival-related signaling
\end{abstract}

Correspondence to: Professor Young Seol Kim, Department of Endocrinology and Metabolism, School of Medicine, Kyung Hee University, 26 Kyunghee-daero, Dongdaemun-gu, Seoul 130-701, Republic of Korea

E-mail: kimys@khmc.or.kr; suhgyber@khmc.or.kr

*Contributed equally

Key words: Chrysanthemum zawadskii, flavonoid, osteoblastic cells, 2-deoxy-D-ribose, oxidative stress, MC3T3-E1 cells pathways. CZE also upregulated the gene expression of the antioxidant enzymes, superoxide dismutase (SOD)2, SOD3 and glutathione peroxidase 4 (GPx4), which was inhibited by dRib. Taken together, these results suggest that CZE attenuates dRibinduced cell damage in osteoblastic cells and may be useful for the treatment of diabetes-associated bone disease.

\section{Introduction}

Chrysanthemums are perennial flowering plants in the Asteraceae family which is native to Asia and northeastern Europe. Extracts of chrysanthemum plants have been shown to have a variety of potential medicinal properties, such as antiAIDS (1,2), antimicrobial (3), antioxidant (4,5) and antimycotic activities (6). Chrysanthemum zawadskii is one of the species of the genus Chrysanthemum and has traditionally been used in folk medicine, known as 'Gujeolcho' in Korea for the treatment of various diseases. Chrysanthemum zawadskii extracts (CZE) has been shown to have anti-inflammatory and anti-oxidative stress activities in RAW 264.7 murine macrophage cells (7) and one of the fractions derived from $\mathrm{CZE}$ exerts protective effects against carbon tetrachloride $\left(\mathrm{CCl}_{4}\right)$-induced hepatotoxicity in mice via the induction of detoxifying enzyme, $\mathrm{NAD}(\mathrm{P}) \mathrm{H}$ : (quinone acceptor) oxidoreductase 1 (8).

Oxidative stress results from a persistent imbalance between antioxidant defenses and the production of highly reactive oxygen species (ROS) (9). Chronic hyperglycemia leads to oxidative stress which is involved in the progression of pancreatic $\beta$-cell deterioration, as well as in the development of diabetic complications (10). Bone complications in diabetes include early onset osteopenia and osteoporosis $(11,12)$. These cause an increase in bone fractures and a delay in the healing of fractures, affecting the quality of life (13). In vitro studies have indicated that oxidative stress inhibits osteoblast differentiation (14) and induces osteoblastic insults and apoptosis (15). One of the mechanisms of diabetes-associated bone disease may be the direct effects on osteoblasts and bone turnover. An imbalance between bone- 
forming osteoblasts and bone-resorbing osteoclasts leads to the pathogenesis and etiology of certain bone metabolic diseases, including osteoporosis and osteopetrosis (16).

Sugars that contain aldehyde groups that are oxidized to carboxylic acids are classified as reducing sugars, and they produce ROS through autoxidation and protein glycosylation (17-19). 2-Deoxy-D-ribose (dRib) is a strong reducing sugar that is highly reactive with proteins $(20,21)$. Since glucose is the least reactive of the reducing sugars and requires longterm exposure to provoke oxidative stress (19), we selected $\mathrm{dRib}$ as a surrogate for glucose to induce oxidative damage in MC3T3-E1 osteoblastic cells. We have previously demonstrated that dRib promotes apoptosis by increasing oxidative stress in HIT-T15 pancreatic $\beta$-cells (20-23) and MC3T3-E1 osteoblastic cells (24-26).

Although it is known that the health beneficial and pharmacological effects of CZE are due to its antioxidant activities, the molecular mechanisms behind its biological effects on bone metabolism are still unknown. Oxidative stress is involved in the modulation of the expression of transcription factors and cellular signaling, which may affect osteoblast function. In the present study, we aimed to investigate the effects of CZE on oxidative stress-induced damage and cellular dysfunction in MC3T3-E1 osteoblastic cells.

\section{Materials and methods}

Plant materials and reagents. The aerial parts of Chrysanthemum zawadskii were collected from Nowha-do, Wando-gun, Jeollanam-do Province, Korea. The botanical origin of the sample was classified by one of the authors (Y.P. Jang) and the voucher specimen (KHUP-289) was deposited in the Kyung Hee Museum of Korean Traditional Herbal Medicine, Seoul, Korea. Dried aerial parts of Chrysanthemum zawadskii $(1 \mathrm{~kg}$ ) were refluxed with $80 \%$ ethanol (in water, $\mathrm{v} / \mathrm{v}$ ) at room temperature several times. This extract was filtered and evaporated in a rotary vacuum evaporator and then finally lyophilized with a freezing dryer. The extract (total yield, $26.7 \%$ ) was dissolved in dimethyl sulfoxide (DMSO) and diluted to the appropriate concentrations with culture medium [final DMSO concentration was $0.05 \%(\mathrm{v} / \mathrm{v})$ ]. Linarin was obtained from ChromaDex (Irvine, CA, USA). High performance liquid chromatography (HPLC) grade acetonitrile was purchased from Fisher Scientific (Seoul, Korea). Formic acid of analytical reagent grade was obtained from Wako Pure Chemical Industries, Ltd. (Osaka, Japan).

HPLC and HPLC-electrospray ionization-tandem mass spectrometry (HPLC-ESI-MS) analysis of CZE. Standard solutions containing linarin were prepared in the concentration range from 50 to $400 \mu \mathrm{g} / \mathrm{ml}$. A total of $5 \mathrm{mg}$ of $80 \%$ ethanolic CZE was dissolved in $1 \mathrm{ml}$ of initial solvent mixture of HPLC [15\% acetonitrile (in water, v/v)]. All the standard and sample solutions were filtered through a $0.45 \mu \mathrm{m}$ syringe filter (Millipore, Bedford, MA, USA) before being subjected to HPLC. HPLC analysis was performed on a Waters system (Waters Corp., Milford, MA, USA) equipped with a photodiode array detector (Waters 996) running with Empower software. A Hector C18 column $(250 \times 4.6 \mathrm{~mm}, 5 \mu \mathrm{m})$ (RStech Co., Ltd., Daejeon, Korea) was selected for the chemical fingerprint analysis of the ethanolic extract of Chrysanthemum zawadskii. The UV data of the effluent from the column ranging from 200 to $400 \mathrm{~nm}$ were collected. The detection wavelength was set to $330 \mathrm{~nm}$. The flow rate was $1 \mathrm{ml} / \mathrm{min}$. The mobile phase comprised $0.1 \%$ formic acid in acetonitrile (solvent $\mathrm{A}$ ) and $0.1 \%$ formic acid in water (solvent B). The gradient program commenced with linear gradient from 15 to $23 \%$ of solvent A for $15 \mathrm{~min}$, followed by isocratic elution for $35 \mathrm{~min}$, then linear gradient to $30 \%$ for $2 \mathrm{~min}$ and isocratic elution for $10 \mathrm{~min}$. The injection volume of the standard and the samples was $10 \mu \mathrm{l}$.

In order to identify major peaks from CZE, HPLC-ESI-MS was performed. The HPLC flow rate was approximately $0.2 \mathrm{ml} / \mathrm{min}$ using a commercial splitter. An AccuTOF ${ }^{\circledR}$ singlereflectron time-of-flight mass spectrometer was equipped with an ESI and operated using Mass Center system version 1.3.7b software (both from Jeol USA Inc., Peabody, MA, USA). In the positive ion mode, the atmospheric pressure interface potentials were typically set to the following values: orifice $1,80 \mathrm{~V}$ and ring lens and orifice 2, 10 and $5 \mathrm{~V}$, respectively. The ion guide potential and detector voltage were set to 2,000 and 2,300 V, respectively. ESI parameters were set as follows: needle electrode $=2,000 \mathrm{~V}$, nitrogen gas was used as a nebulizer, desolvating and the flow rate was 1 and $3 \mathrm{l} / \mathrm{min}$, desolvating chamber temperature, $250^{\circ} \mathrm{C}$, orifice 1 temperature, $80^{\circ} \mathrm{C}$. Mass scale calibration was performed using the YOKUDELNA calibration kit (Jeol Ltd., Tokyo, Japan) for accurate mass measurements and calculations of the elemental composition. MS acquisition was set with a scan range of $\mathrm{m} / \mathrm{z} 100$ to 2,000 .

Cell culture. MC3T3-E1 murine osteoblastic cells were obtained from the American Type Culture Collection (Rockville, MD, USA). The cells were cultured in $\alpha$-modified minimal essential medium ( $\alpha$-MEM; Invitrogen, Carlsbad, CA, USA) supplemented with $10 \%$ fetal bovine serum (FBS; Sigma Chemical Co., St. Louis, MO, USA), $100 \mu \mathrm{U} / \mathrm{ml}$ penicillin, and $100 \mu \mathrm{g} / \mathrm{ml}$ streptomycin. The cultures were maintained at $37^{\circ} \mathrm{C}$ in a humidified $5 \% \mathrm{CO}_{2}$ atmosphere and subcultured by trypsinization with $0.05 \%$ trypsin- $0.02 \%$ EDTA in $\mathrm{Ca}^{2+}$ - and $\mathrm{Mg}^{2+}$-free Dulbecco's phosphate-buffered saline (DPBS) until they reached approximately $70 \%$ confluence. For assessment of cell viability, apoptosis and ROS production, the cells were plated in 24-well culture plates at a density of $2 \times 10^{4}$ cells/well. Two days after culture, the cells were treated with CZE for $24 \mathrm{~h}$ in $\alpha$-MEM containing $0.5 \%$ FBS. The cells were also seeded in a 6 -well culture plate at a density of $1 \times 10^{5}$ cells/well and treated with culture medium containing $10 \mathrm{mM} \beta$-glycerophosphate and $50 \mu \mathrm{g} / \mathrm{ml}$ ascorbic acid to initiate in vitro mineralization as previously described (27). The cell culture medium was changed every 2 days. After 6 days, the cells were cultured in medium containing dRib and/or CZE for 2 days and the alkaline phosphatase (ALP) activity, collagen content and gene expression were then measured.

Assessment of cell viability. Cell viability was determined by measuring cell metabolic activity using the Cell Counting kit-8 (CCK-8) (Dojindo Co., Kumamoto, Japan) (28). CCK-8 contains 2-(2-methoxy-4-nitrophenyl)-3-(4-nitrophenyl)5-(2,4-disulfophenyl)-2H-tetrazolium, monosodium salt (WST-8), which produces a water-soluble formazan dye upon reduction in the presence of an electron carrier. The amount of 
yellow formazan dye generated by the activity of dehydrogenases in the cells is directly proportional to the number of living cells. MC3T3-E1 osteoblastic cells were plated in 24-well cell culture plates at a density of $2 \times 10^{4}$ cells/well. At the end of the culture period, $50 \mu \mathrm{l}$ of the CCK- 8 solution were added to each well of the culture plate, which contained $500 \mu \mathrm{l}$ of medium. After a 4-h incubation, the absorbance was measured using a Zenyth 3100 multimode detector (Anthos Labtec Instruments $\mathrm{GmbH}$, Wals/Salzburg, Austria) at $450 \mathrm{~nm}$ using a $650 \mathrm{~nm}$ filter as a reference. Cells incubated with culture medium alone were used to determine $100 \%$ viability and were included as the control in all the experiments to allow the estimation of the percentage viability of the cell samples.

Apoptosis determination by ELISA. A cell death ELISA kit (Roche Molecular Biochemicals, Mannheim, Germany), which quantitatively detects cytosolic histone-associated DNA fragments, was used to measure apoptosis according to the manufacturer's instructions. Briefly, cells were seeded at a density of $2 \times 10^{4}$ cells in 24 -well culture plates. The culture conditions used were the same as those described for the cell viability assay. Following incubation, the cells were lysed and the intact nuclei were pelleted by centrifugation. An aliquot of supernatant was used as the antigen source for sandwich ELISA using a primary anti-histone monoclonal antibody that was bound to the streptavidin-coated wells of a microtiter plate. Subsequently, the cells were treated with a second anti-DNA monoclonal antibody coupled to peroxidase. Nucleosome levels were quantified by determining the amount of peroxidase retained in the immunocomplex. Peroxidase activity was determined photometrically at $405 \mathrm{~nm}$ using 2,2'-azinodi(3-ethylbenzthiazolin-sulfonate) (ABTS) as the substrate.

Measurement of ROS. The fluorescent probe, chloromethyl2,7-dichlorodihydrofluorescein diacetate (DCFDA; Molecular Probes, Eugene, OR, USA), was used to measure intracellular ROS levels as previously described (28). MC3T3-E1 osteoblastic cells were cultured for $24 \mathrm{~h}$ in $\alpha$-MEM containing $0.5 \%$ FBS, rinsed twice with DPBS, and then treated with $10 \mu \mathrm{M}$ of DCFDA for $1 \mathrm{~h}$. The cells were then rinsed, scraped and their fluorescence was measured (excitation $485 \mathrm{~nm}$, emission $515 \mathrm{~nm}$ ) using a Zenyth 3100 multimode detector.

ALP activity. At the time of cell harvesting, the medium was removed and the cell monolayer was gently washed twice with PBS. The cells were then lysed with $0.2 \%$ Triton X-100 and the lysate was centrifuged at $14,000 \mathrm{x}$ g for $5 \mathrm{~min}$. The cleared supernatant was used for the measurement of ALP activity and protein concentration. ALP activity was determined using an ALP activity assay kit (Somang Engineering Co., Seoul, Korea) and normalized using the number of cells.

Collagen content. Cellular collagen content was measured using a Sircol Collagen Assay kit (Biocolor Ltd., Newtownabbey, Northern Ireland). This assay is a quantitative dye-binding method designed for the analysis of collagen extracted from mammalian tissues and cells during in vitro culture. The dye reagent binds specifically to the $[\mathrm{Gly}-\mathrm{X}-\mathrm{Y}]_{\mathrm{n}}$ helical structure found in mammalian collagen (types I-V). Measurements were normalized using the number of cells.
RNA extraction. Total RNA was isolated from the cells using TRIzol reagent (Invitrogen). Following isolation, RNA integrity was assessed using an Agilent 2100 Bioanalyzer (Agilent Technologies, Inc., Palo Alto, CA, USA). cDNA was synthesized using the Transcriptor First Strand cDNA synthesis kit (Roche Diagnostics GmbH, Mannheim, Germany) and stored at $-70^{\circ} \mathrm{C}$ until further processing. All procedures were carried out according to the manufacturer's instructions.

Real-time RT-PCR. Real-time PCR was performed to verify the differential expression of selected genes using a Roche LightCycler 480 system (Roche Diagnostics $\mathrm{GmbH}$ ) and the TaqMan method using the Roche Universal Probe Library (UPL) kit. Relative gene expression was determined by employing the comparative $\mathrm{CT}$ method. All reactions were carried out in a total volume of $20 \mu \mathrm{l}$ of reaction mixture containing $10.0 \mu \mathrm{l}$ of $2 \mathrm{X}$ UPL master mix, $1.0 \mu \mathrm{l}$ of $5^{\prime}$ primer (10 pmol $/ \mu \mathrm{l}), 1.0 \mu \mathrm{l}$ of $3^{\prime}$ primer $(10 \mathrm{pmol} / \mathrm{ml}), 0.2 \mu \mathrm{l}$ of UPL probe, $1.0 \mu \mathrm{l}$ of cDNA and $6.8 \mu \mathrm{l}$ of sterile water. The thermal cycling conditions for PCR were an initial denaturation for $10 \mathrm{~min}$ at $95^{\circ} \mathrm{C}$, followed by 40 cycles of $94^{\circ} \mathrm{C}$ for $10 \mathrm{sec}$ and $60^{\circ} \mathrm{C}$ for $30 \mathrm{sec}$. The primers summarized in Table I were designed using the Roche ProbeFinder assay tool. For RT-PCR analysis, duplicate PCRs were carried out for each cDNA. Negative controls (except templates) were included in the PCR reaction to ensure specific amplification. LightCycler 480 software version 1.2 (Roche Diagnostics $\mathrm{GmbH}$ ) was used for the analysis of the quantitative PCR. The values obtained from each sample were normalized to hypoxanthine guanine phosphoribosyltransferase (HPRT) expression. The levels of each gene expression in all experimental groups were compared to the expression levels of the control group.

Statistical analysis. All results are expressed as the means \pm SD. Statistical analysis was performed using one-way ANOVA with a subsequent Tukey's multiple comparison test. A P-value $<0.05$ was considered to indicate a statistically significant difference. Statistical analysis was performed using SAS software (SAS Inc., Cary, NC, USA).

\section{Results and Discussion}

To our knowledge, this is the first study to investigate the effects of CZE on dRib-induced oxidative damage using a MC3T3-E1 osteoblastic culture model. One of the mechanisms of diabetesassociated bone disease may be the direct effects on osteoblastic cells. In vitro studies have shown that hyperglycemia inhibits osteoblastic cell proliferation and differentiation $(29,30)$, indicating that extracellular high glucose directly impairs osteoblastic function, resulting in bone disease. In our previous studies, we demonstrated that dRib induced cellular damage in pancreatic $\beta$-cells by increasing oxidative stress and protein glycation (20-23). Recently, we also reported that dRib induces cellular dysfunction and apoptosis in the MC3T3-E1 mouse osteoblastic cell line by increasing oxidative stress (26).

Due to the absence of a previous HPLC fingerprint study on CZE, we aimed to establish a HPLC profiling method. Gradient elution system was the best choice to obtain an entire HPLC profile of the secondary metabolites from this plant. An optimized HPLC chromatogram is shown in Fig. 1. Compared 
Table I. Primer sequences used in this study.

\begin{tabular}{|c|c|}
\hline Genes & Primer sequences \\
\hline KT1 & $\begin{array}{l}\text { 5'-TCG TGT GGC AGG ATG TGT AT-3' } \\
\text { 5'-ACC TGG TGT CAG TCT CAG AGG-3' }\end{array}$ \\
\hline $\mathrm{KT} 2$ & $\begin{array}{l}\text { 5'-CGA CCC AAC ACC TTT GTC A-3' } \\
\text { 5'-GAT AGC CCG CAT CCA CTC T-3' }\end{array}$ \\
\hline KT3 & $\begin{array}{l}\text { 5'-TGG ACC ACT GTT ATA GAG AGA AC } \\
\text { 5'-TGG ATA GCT TCC GTC CAC TC-3' }\end{array}$ \\
\hline ALP & $\begin{array}{l}\text { 5'-GGC CAG CTA CAC CAC AAC A-3' } \\
\text { 5'-CTG AGC GTT GGT GTT ATA TGT CTT }\end{array}$ \\
\hline BMP2 & $\begin{array}{l}\text { 5'-GGT CAC AGA TAA GGC CAT TGC-3' } \\
\text { 5'-GCT TCC GCT GTT TGT GTT TG-3' }\end{array}$ \\
\hline BMP4 & $\begin{array}{l}\text { 5'-GAG GAG TTT CCA TCA CGA AGA-3' } \\
\text { 5'-GCT CTG CCG AGG AGA TCA-3' }\end{array}$ \\
\hline BMP7 & $\begin{array}{l}\text { 5'-CGA TAC CAC CAT CGG GAG TTC-3' } \\
\text { 5'-AAG GTC TCG TTG TCA AAT CGC-3' }\end{array}$ \\
\hline BSP & $\begin{array}{l}\text { 5'-GAA AAT GGA GAC GGC GAT AG-3' } \\
\text { 5'-CAT TGT TTT CCT CTT CGT TTG A-3' }\end{array}$ \\
\hline Collagen & $\begin{array}{l}\text { 5'-AGA CAT GTT CAG CTT TGT GGA C-3' } \\
\text { 5'-GCA GCT GAC TTC AGG GAT G-3' }\end{array}$ \\
\hline GPx1 & $\begin{array}{l}\text { 5'-GGT TTC CCG TGC AAT CAG T-3' } \\
\text { 5'-TCG GAC GTA CTT GAG GGA AT-3' }\end{array}$ \\
\hline GPx4 & $\begin{array}{l}\text { 5'-TAA GAA CGG CTG CGT GGT-3' } \\
\text { 5'-GTA GGG GCA CAC ACT TGT AGG-3' }\end{array}$ \\
\hline OPG & $\begin{array}{l}\text { 5'-ATG AAC AAG TGG CTG TGC TG-3' } \\
\text { 5'-CAG TTT CTG GGT CAT AAT GCA A-3' }\end{array}$ \\
\hline OPN & $\begin{array}{l}\text { 5'-TGA GAT TGG CAG TGA TTT GC-3' } \\
\text { 5'-ATC TGG GTG CAG GCT GTA AA-3' }\end{array}$ \\
\hline $\mathrm{OC}$ & $\begin{array}{l}\text { 5'-CAC CAT GAG GAC CCT CTC TC-3' } \\
\text { 5'-TGG ACA TGA AGG CTT TGT CA-3' }\end{array}$ \\
\hline
\end{tabular}

PI3K 5'-TTT GGG AGA CTG AAT CTC TGG-3' 5'-GTG GCA TCC TTT ACA ATC TCG-3'

SOD1 5'-CCA TCA GTA TGG GGA CAA TAC A-3' 5'-GGT CTC CAA CAT GCC TCT CT-3'

SOD2 5'-GAC CCA TTG CAA GGA ACA A-3' 5'-GTA GTA AGC GTG CTC CCA CAC-3'

SOD3 5'-GGG GAG GCA ACT CAG AGG-3' 5'-TGG CTG AGG TTC TCT GCA C-3'

AKT, protein kinase B; ALP, alkaline phosphatase; BMP, bone morphogenetic protein; BSP, bone sialoprotein; GPx1, glutathione peroxidase 1; OPG, osteoprotegerin; OPN, osteopontin; OC, osteocalcin; PI3K, phosphatidylinositol 3-kinase; SOD, superoxide dismutase.

to the main active compound from a previous report, linarin was identified from the chromatogram (31). A calibration curve was established using methanol stock solution containing linarin diluted to the appropriate concentration. The co-efficient value $\left(r^{2}\right)$ was 0.996 , linearity in this range was sufficient to provide a highly accurate value for the linarin content in the samples. The relative standard deviation (RSD) was $<5.5 \%$. Using the established calibration curves, the content of linarin in the extract was quantified. The calculated content of linarin in the extract was $4.05 \pm 0.27 \%$ (w/w) (Table II).

The retention time, observed mass, mass difference and proposed compounds of 3 peaks are listed in Table III. From the mass spectra, major ion peaks 1-3 contributed to the protonated molecular ion of $\mathrm{m} / \mathrm{z} 355,517$ and 517, respectively. Comparing the reference molecular weight and UV-Visible absorption spectrum, peak 1 corresponds to that of caffeoylquinic acid $(32,33)$. Since caffeoylquinic acid has the same molecular weight and UV-Visible absorption spectrum, it is difficult to assign the exact identification of the peak only by HPLC-(diode-array detection) DAD-MS. Considering the UV-Visible absorption spectrum and molecular weight, unidentified peaks 2 and 3 are supposed to be isomers of dicaffeoylquinic acids (Table III). In order to elucidate the exact identity of the peaks, further sets of experiments, including semi-quantitative scale isolation and spectroscopical analysis are required.

To evaluate the effect of dRib on MC3T3-E1 osteoblastic cell survival, cell viability was determined using the CCK-8 assay. We observed a dose-dependent decrease in cell viability in the cells exposed to various concentrations of $\mathrm{dRib}$ for $24 \mathrm{~h}$ (Fig. 2A). Based on the results of these viability assays, we used $20 \mathrm{mM}$ dRib in subsequent biochemical assays. At this concentration, approximately $50 \%$ inhibition of cell viability occurred in $24 \mathrm{~h}$ under our experimental culture conditions.

To evaluate the effect of CZE on MC3T3-E1 osteoblastic cell survival, the cells were incubated in $\alpha$-MEM containing $0.5 \%$ FBS with increasing concentrations of CZE (0.001$0.1 \mathrm{mg} / \mathrm{ml}$ ) for $24 \mathrm{~h}$ and then cell viability was determined. CZE at these concentrations had no effect on cell viability (Fig. 2B), while higher doses $(>0.1 \mathrm{mg} / \mathrm{ml})$ were cytotoxic (data not shown).

To determine whether CZE has an effect on the dRibinduced decrease in cell survival, cells were pre-incubated with CZE for $30 \mathrm{~min}$ and then cultured with $20 \mathrm{mM} \mathrm{dRib}$ for $24 \mathrm{~h}$. CCK-8 assays revealed that CZE $(0.01-0.05 \mathrm{mg} / \mathrm{ml})$ partially reversed the $\mathrm{dRib}$-mediated reduction in cell viability in a dose-dependent manner (Fig. 2B). Therefore, we selected the highest non-toxic concentration of CZE $(0.01$ and $0.05 \mathrm{mg}$ ) $\mathrm{ml})$ for all subsequent cell culture experiments. The antioxidant, $N$-acetyl- $L$-cysteine (NAC), was used to investigate the mechanism of dRib-induced cell damage. Pre-treatment of the cells with $10 \mathrm{mM}$ NAC almost completely reversed the dRib-induced cytotoxicity. These findings suggest that the dRib-induced cytotoxicity was most likely due to oxidative stress-induced effects. In a recent study, we showed that the antioxidants, NAC and $\alpha$-lipoic acid (ALA), almost reversed the dRib-mediated reduction in the viability of MC3T3-E1 osteoblastic cells (26). Morphological changes were compared between the dRib-treated and control cells under an inverted microscope. The control cells were flat, polygonal in shape and arranged in a monolayer. Following exposure to dRib for $24 \mathrm{~h}$, the cells were degenerated and had a spindle-shaped appearance. CZE improved the morphological changes of osteoblastic cells induced by dRib (Fig. 2C). 
Table II. Regression data, precision and quantification of linarin from the $80 \%$ ethanolic extract of Chrysanthemum zawadskii.

\begin{tabular}{lccccc}
\hline Compound & Regression equation & $\mathrm{R}^{2}$ & $\begin{array}{c}\text { Linear range } \\
(\mu \mathrm{g} / \mathrm{ml})\end{array}$ & $\begin{array}{c}\mathrm{RSD}(\%) \\
(\mathrm{n}=3)\end{array}$ & $\begin{array}{c}\text { Contents of linarin in 80\% } \\
\text { ethanolic extract }(\mu \mathrm{g} / \mathrm{mg})\end{array}$ \\
\hline Linarin & $\mathrm{y}=19,819 \mathrm{x}+31,363$ & 0.996 & $50-200$ & $1.2-5.5$ & $40.57 \pm 2.72$ \\
\hline
\end{tabular}

RSD, relative standard deviation.

Table III. The observed and calculated mass numbers of HPLC peaks of CZE.

\begin{tabular}{lccccc}
\hline Peak no. & $\begin{array}{c}\text { Rt } \\
(\mathrm{min})\end{array}$ & $\begin{array}{c}\text { Theoretical mass } \\
{[\mathrm{M}+\mathrm{H}]^{+}}\end{array}$ & $\begin{array}{c}\text { Observed mass } \\
{[\mathrm{M}+\mathrm{H}]^{+}}\end{array}$ & $\begin{array}{c}\text { Mass difference } \\
(\mathrm{mmu})\end{array}$ & $\begin{array}{l}\text { Identification } \\
1\end{array}$ \\
\hline 6.55 & 355.10291 & 355.09980 & -3.11 & Caffeoylquinic acid \\
3 & 23.76 & 517.13460 & 517.13413 & -0.47 & Dicaffeoylquinic acid \\
& 25.90 & 517.13460 & 517.13498 & 0.38 & Dicaffeoylquinic acid \\
\hline
\end{tabular}

HPLC, high performance liquid chromatography; CZE, Chrysanthemum zawadskii extract.

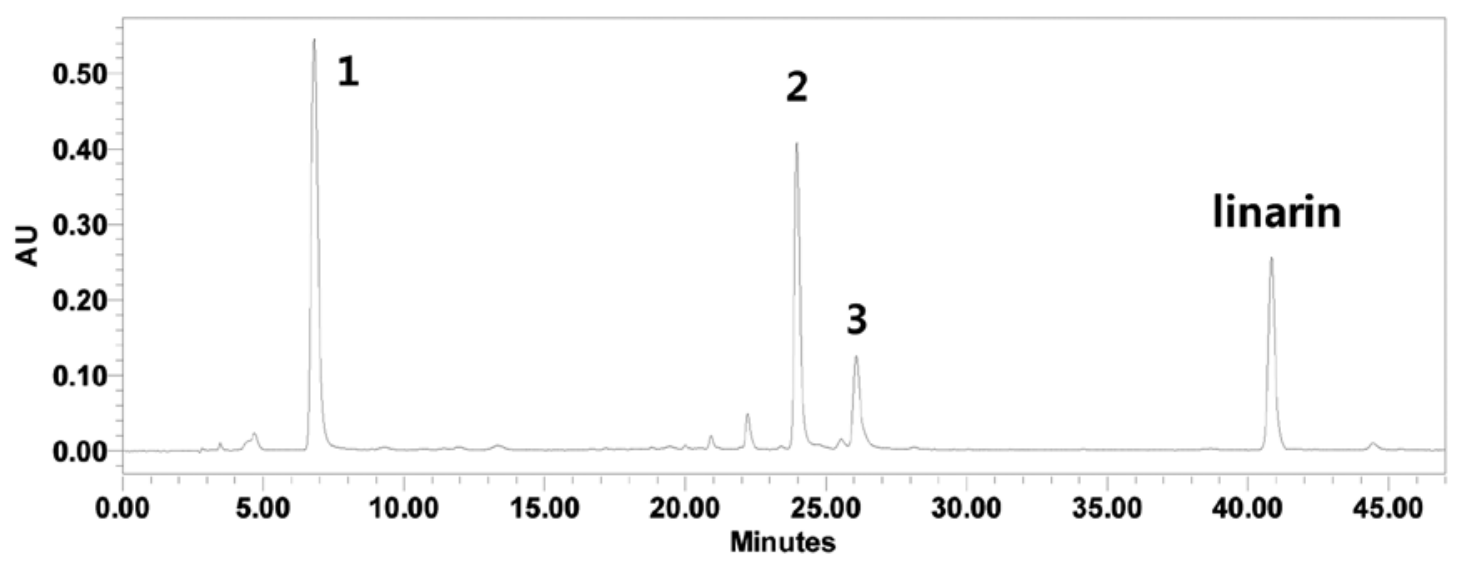

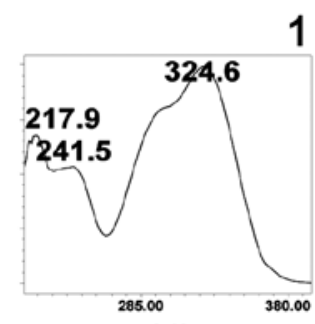

nm
1

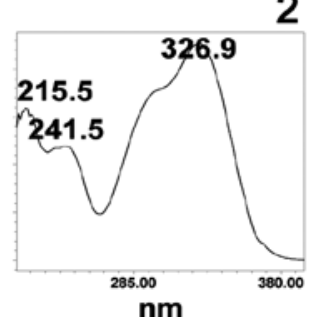

3

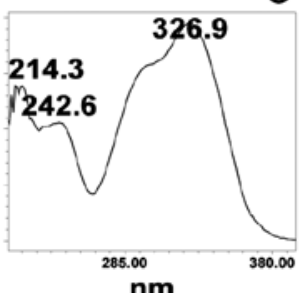

$\mathrm{nm}$

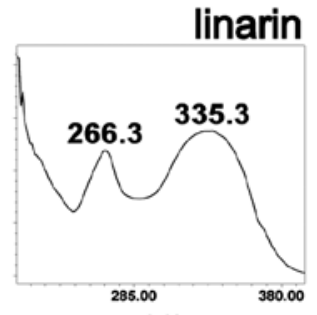

$\mathbf{n m}$

Figure 1. High performance liquid chromatography (HPLC) chromatogram of the ethanolic of Chrysanthemum zawadskii extract (CZE) and UV-Visible absorption spectra of major peaks.

The oxidative stress caused by dRib in MC3T3-E1 osteoblastic cells was evaluated by measuring ROS generation and apoptosis. Oxidative stress may initiate a mitochondrial permeability transition event, which is an early mediator of cellular apoptosis. When the cells were treated with $20 \mathrm{mM}$ dRib, ROS generation and apoptosis increased, while treatment with CZE $(0.05 \mathrm{mg} / \mathrm{ml})$ in the presence of $\mathrm{dRib}$ attenuated all the dRib-induced effects (Fig. 3). We used the antioxidant, NAC, to investigate the effect of oxidative stress on the cells. NAC prevented the dRib-induced cellular effects. These data are consistent with those from previous our studies, indicating that the antioxidants, NAC and ALA, protect pancreatic $\beta$-cells and MC3T3-E1 osteoblastic cells against oxidative stress, as shown by a reduction in ROS generation 

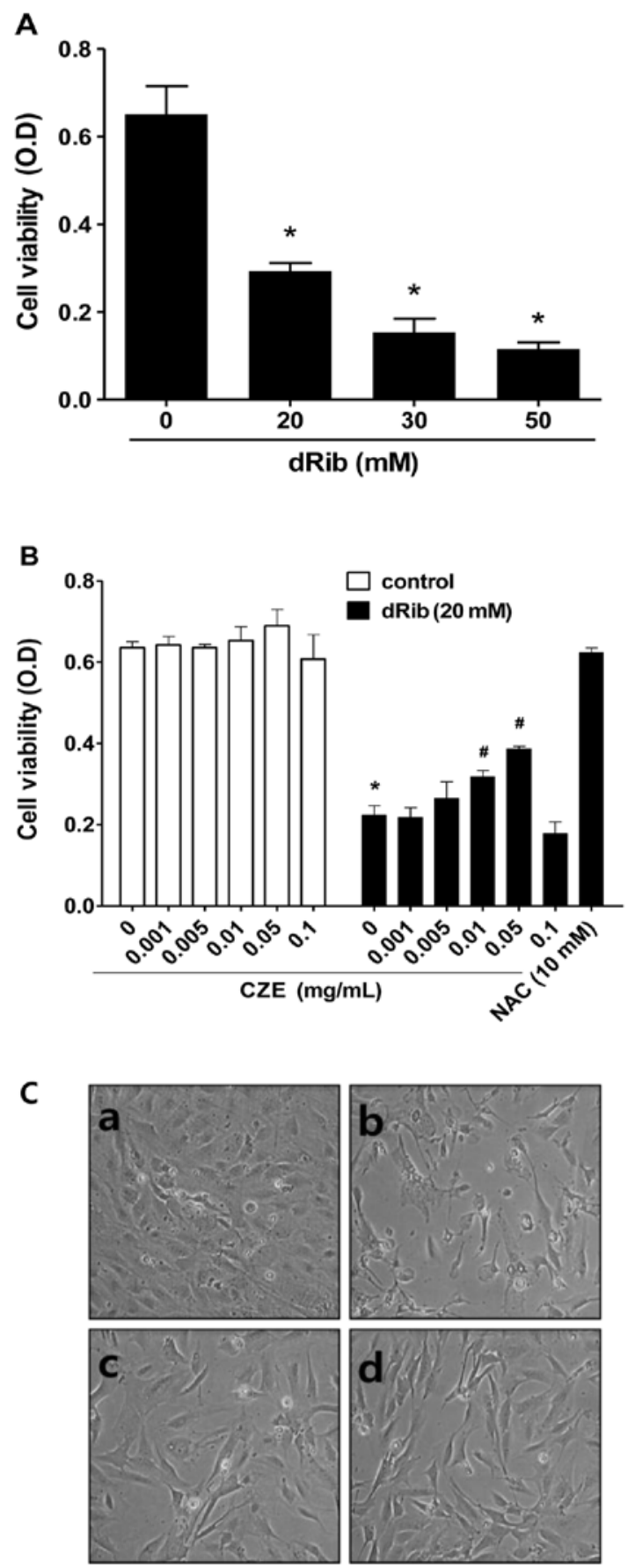

Figure 2. Protective effects of Chrysanthemum zawadskii extract (CZE) on 2-deoxy-D-ribose (dRib)-induced decrease in osteoblastic cell viability. (A) Effect of dRib on cell viability of osteoblastic cells. Cells were treated with various concentrations of dRib. (B) Cells were cultured with an increasing concentration of CZE in the presence or absence of $20 \mathrm{mM}$ dRib. Cells were pre-incubated with CZE or $N$-acetyl- $L$-cysteine (NAC) for 30 min at the indicated concentrations and then cultured with $20 \mathrm{mM} \mathrm{dRib}$ for 24 h. Cell viability was determined using the Cell Counting kit-8 (CCK-8). (C) Morphological changes were photographed under an inverted microscope. (a) control; (b) dRib; (c) dRib + $0.01 \mathrm{mg} / \mathrm{ml} \mathrm{CZE;} \mathrm{(d)} \mathrm{dRib} \mathrm{+} 0.05 \mathrm{mg} / \mathrm{ml} \mathrm{CZE}$. The data are expressed as the means \pm SD of 4 independent determinations, each performed in quadruplicate. ${ }^{*} \mathrm{P}<0.05$ vs. untreated control; ${ }^{*} \mathrm{P}<0.05$ vs. dRib-treated cells.

and apoptosis (20-22,26,28). These findings indicate that CZE can function as an antioxidant and thereby protect MC3T3-E1 osteoblastic cells from dRib-induced oxidative cell damage.
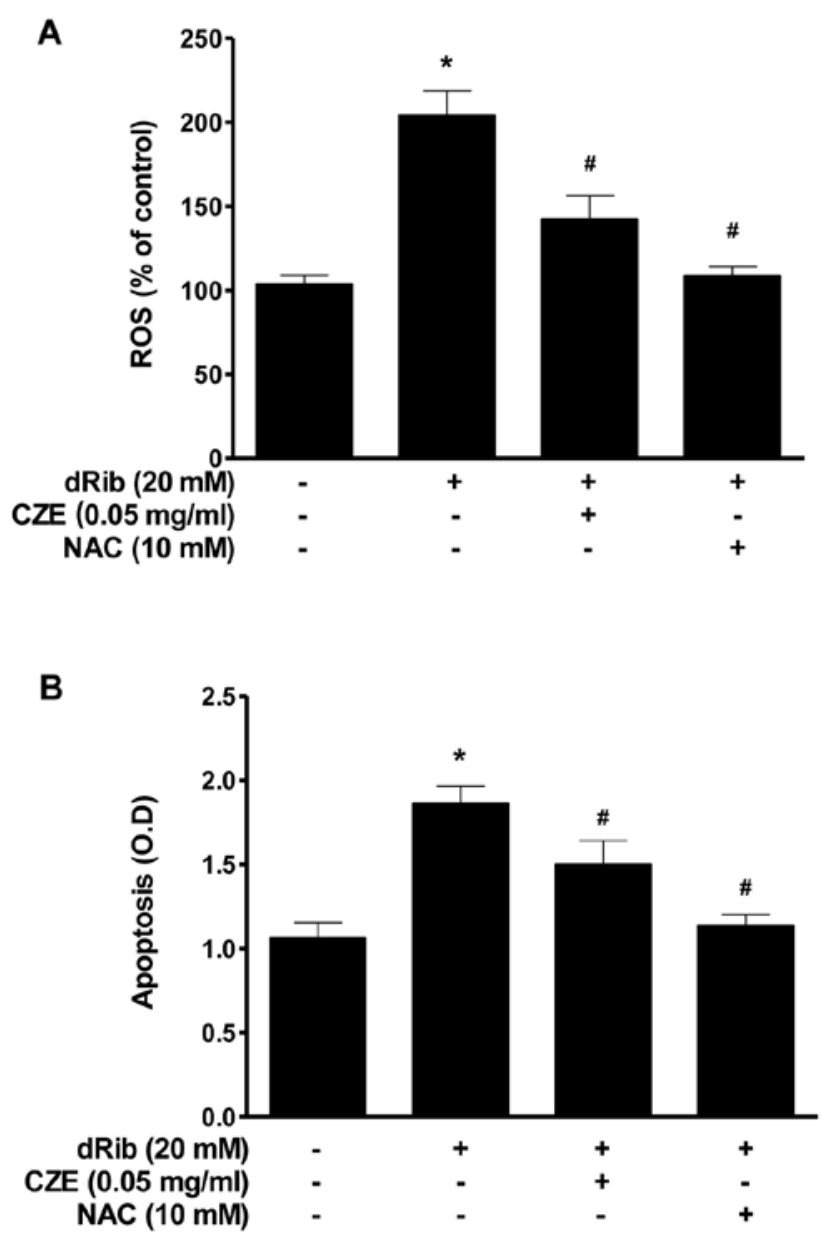

Figure 3. Effect of Chrysanthemum zawadskii extract (CZE) on 2-deoxyD-ribose (dRib)-induced reactive oxygen species (ROS) (A) production and (B) apoptosis in osteoblastic cells. Cells were pre-incubated with $0.05 \mathrm{mg}$ / $\mathrm{ml} \mathrm{CZE}$ or $10 \mathrm{mM} N$-acetyl- $L$-cysteine (NAC) for $30 \mathrm{~min}$ and then cultured with $20 \mathrm{mM} \mathrm{dRib}$ for $24 \mathrm{~h}$. The data are expressed as the means \pm SD of 3 independent determinations, each performed in quadruplicate. ${ }^{*} \mathrm{P}<0.05$ vs. untreated control. ${ }^{~} \mathrm{P}<0.05$ vs. dRib-treated cells.

MC3T3-E1 cells are an osteoblastic precursor cell line which was cloned from newborn mouse calvaria (34), and it is frequently used to study osteoblast differentiation. Osteoblast differentiation is the primary event of bone formation. Bone ALP is a glycoprotein localized in the plasma membrane of osteoblastic cells which is one of the osteoblastic phenotype markers (35). Alterations in its activity have been observed in osteoporosis and other metabolic bone diseases. High levels of ALP activity have been observed in both pre-osteoblasts and osteoblasts in vivo and in differentiating osteoblasts in vitro. Osteoblastic cells produce type I collagen, which is the most abundant protein in the bone matrix, serves an early marker of osteoblast differentiation, and is the major organic component of mineralized bone matrix (36). The present study demonstrates that the reducing sugar, dRib, exerts a profound inhibitory effect on osteoblastic cell differentiation; however, when osteoblastic cells were treated with CZE in the presence of $20 \mathrm{mM} \mathrm{dRib}$, significant increases in the major osteoblast-specific ALP activity and collagen content were observed (Fig. 4).

In addition to measuring the levels of the differentiation marker, ALP and collagen, we evaluated the differentiated 
A
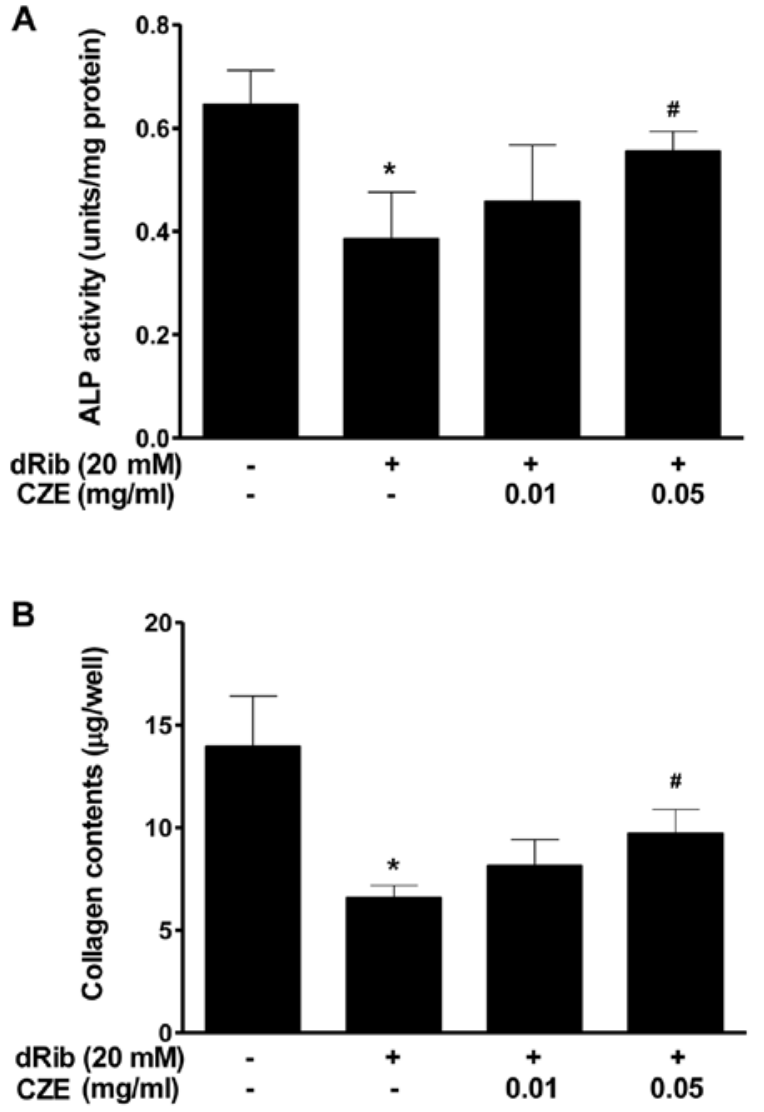

Figure 4. Effects of Chrysanthemum zawadskii extract (CZE) on (A) 2-deoxyD-ribose (dRib)-induced alkaline phosphatase (ALP) activity and (B) collagen content. Cells were preincubated with CZE and then cultured with $20 \mathrm{mM}$ dRib. ALP activity and collagen content were assessed as described in Materials and methods. The data are expressed as the means \pm SD of 3 independent determinations, each performed in quadruplicate. " $\mathrm{P}<0.05$ vs. untreated control; ${ }^{\#} \mathrm{P}<0.05$ vs. dRib-treated cells.

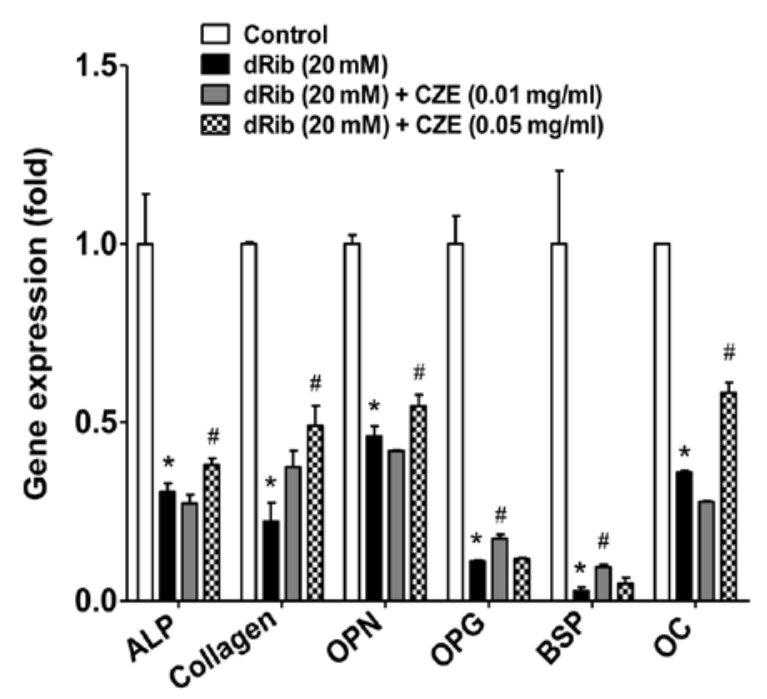

Figure 5. Effect of Chrysanthemum zawadskii extract (CZE) on 2-deoxy-Dribose (dRib)-induced gene expression involved in osteoblast differentiation. Total RNA was extracted from osteoblastic cells and the mRNA levels for alkaline phosphatase (ALP), collagen, osteopontin (OPN), osteoprotegerin (OPG), bone sialoprotein (BSP) and osteocalcin (OC) were assessed by realtime PCR as described in Materials and methods. The data are expressed as the means $\pm \mathrm{SD}$ of 3 independent determinations. ${ }^{*} \mathrm{P}<0.05$ vs. untreated control; ${ }^{\#} \mathrm{P}<0.05$ vs. dRib-treated cells.

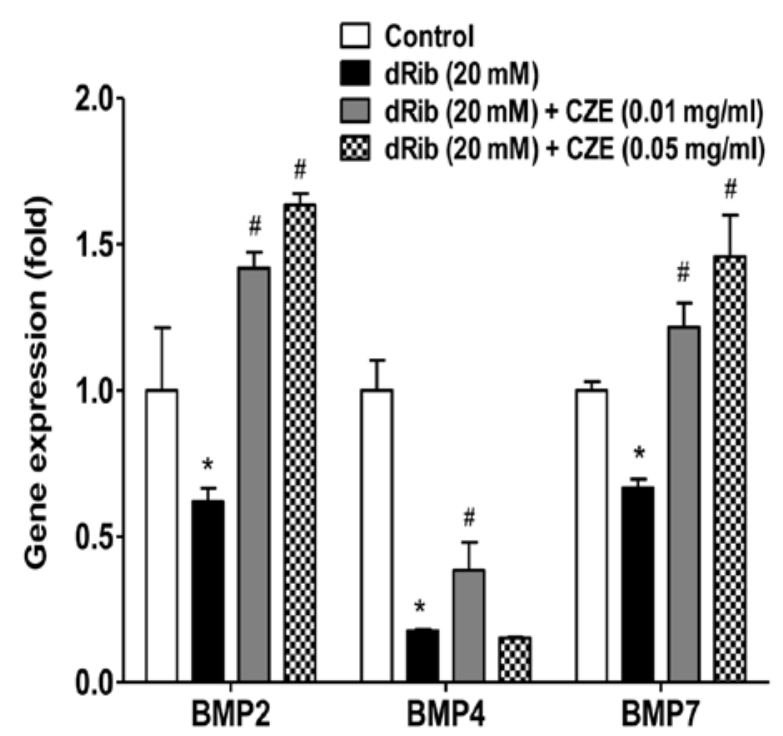

Figure 6. Effect of Chrysanthemum zawadskii extract (CZE) on 2-deoxy-Dribose (dRib)-induced bone morphogenetic proteins (BMP) gene expression in osteoblastic cells. Total RNA was extracted from osteoblastic cells and the mRNA levels for BMP2, BMP4 and BMP7 were assessed by real-time PCR as described in Materials and methods. The data are expressed as the means \pm SD of 3 independent determinations. ${ }^{*} \mathrm{P}<0.05$ vs. untreated control; ${ }^{\#} \mathrm{P}<0.05$ vs. dRib-treated cells.

function of the osteoblastic cells at the transcriptional level. We analyzed the gene expression of a number of molecular markers of osteoblast differentiation. Osteopontin (OPN) is a major acidic phosphorylated glycoprotein secreted by osteoblasts and acts as a regulator of bone formation (37). Osteoprotegerin $(\mathrm{OPG})$, produced by osteoblasts is one of the regulators of bone metabolism and inhibits bone resorption by regulating the unction of osteoclasts (38). Bone sialoprotein (BSP) is thought to function in the initial mineralization of bone and may be crucial for osteoblast differentiation. The flavonoid, kaempferol, has been shown to stimulate BSP gene transcription and new bone formation (39). Thus, these molecular markers are important and best known regulators of osteoblast function. In this study, osteoblastic cells were treated with $\mathrm{dRib}$ in the presence or absence of CZE. Six differentiation makers [ALP, collagen, OPN, OPG, BSP and osteocalcin (OC)] were downregulated in response to exposure to $\mathrm{dRib}$; however, treatment with CZE partially inhibited the dRib-induced downregulation of gene expression of the differentiation markers (Fig. 5).

Bone morphogenetic proteins (BMPs) are known to be the most potent regulators of osteoblast differentiation among many local factors. MC3T3-E1 cells are highly BMP-responsive and can complete the differentiation process in long term culture. BMPs stimulate ALP activity, collagen synthesis, parathyroid hormone (PTH) responsiveness and OC production in osteoblastic cells (40-41), suggesting that BMPs stimulate the differentiation of osteoblastic cells. The present study demonstrates that the reducing sugar, $\mathrm{dRib}$, exerts a profound inhibitory effect on the gene expression of BMPs; however, when the osteoblastic cells were treated with CZE in the presence of $20 \mathrm{mM} \mathrm{dRib}$, the expression of BMPs, including BMP2, BMP4 and BMP7 was significantly increased (Fig. 6). These results suggest that CZE exerts a positive effect on the 


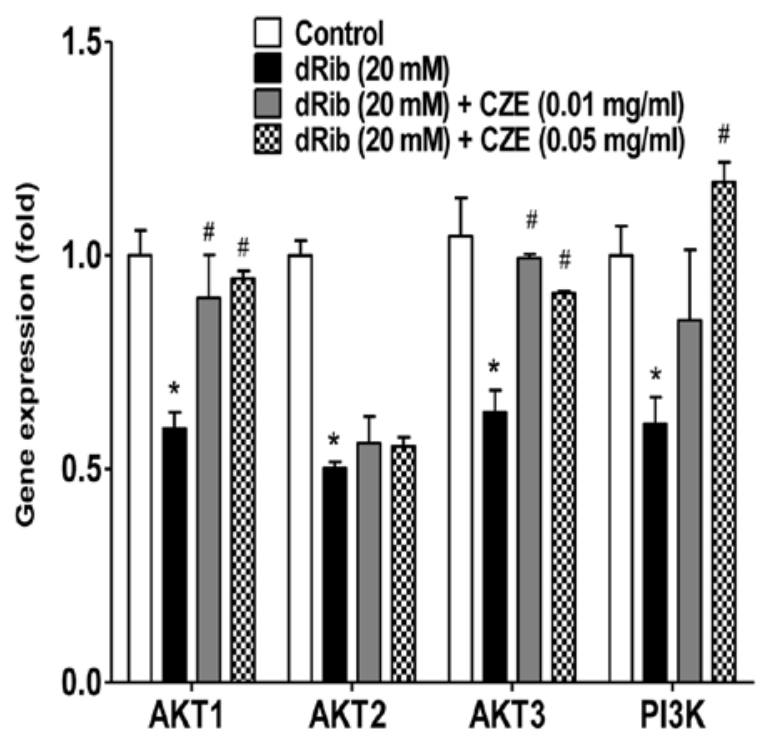

Figure 7. Effect of Chrysanthemum zawadskii extract (CZE) on 2-deoxy-Dribose (dRib)-induced gene expression involved in osteoblastic cell survival Total RNA was extracted from osteoblastic cells and the mRNA levels for phosphatidylinositol 3-kinase (PI3K), protein kinase B1 (AKT1), AKT2 and AKT3 were assessed by real-time PCR as described in Materials and methods. The data are expressed as the means \pm SD of 3 independent determinations ${ }^{*} \mathrm{P}<0.05$ vs. untreated control; ${ }^{\#} \mathrm{P}<0.05$ vs. dRib-treated cells.

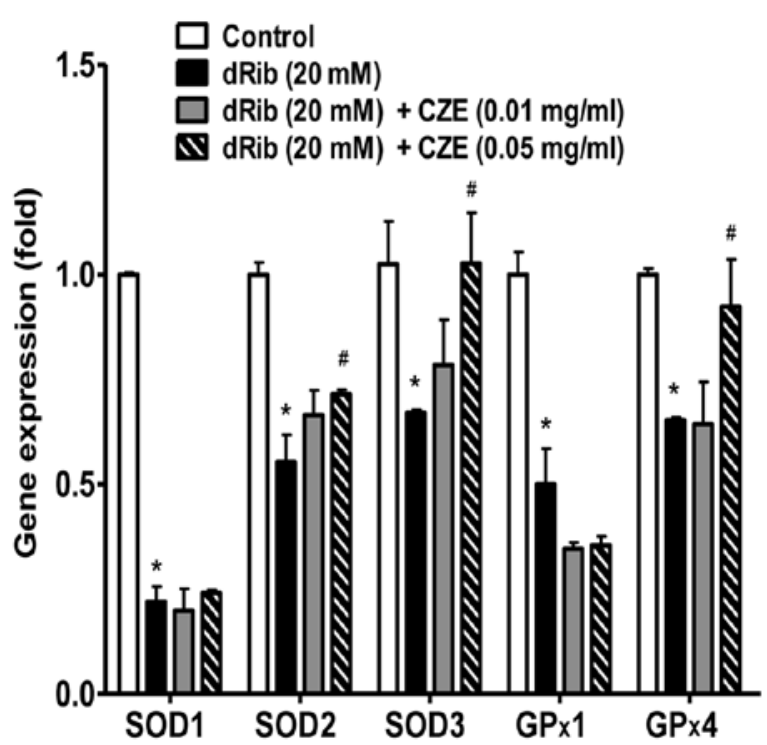

Figure 8. Effect of Chrysanthemum zawadskii extract (CZE) on 2-deoxy-Dribose (dRib)-induced gene expression involved in osteoblastic anti-oxidant enzymes. Total RNA was extracted from osteoblastic cells and the mRNA levels for superoxide dismutase 1 (SOD1), SOD2, SOD3, glutathione peroxidase 1 (GPx1) and GPx4 were assessed by real-time PCR as described in Materials and methods. The data are expressed as the means \pm SD of 3 independent determinations. ${ }^{*} \mathrm{P}<0.05$ vs. untreated control; ${ }^{\#} \mathrm{P}<0.05$ vs. dRib-treated cells.

differentiation of osteoblastic cells through the stimulation of BMP production.

The phosphatidylinositol 3-kinase (PI3K)-protein kinase B (AKT) signaling pathway is activated by many types of cellular stimuli or toxic insults and regulates fundamental cellular functions, such as transcription, translation, proliferation, growth and survival (42). One important function of activated PI3K in cells is the inhibition of apoptosis (43). AKT is a good candidate for mediating these PI3K-dependent cell survival responses. AKT has been implicated as an anti-apoptotic factor in several different cell death paradigms, including the withdrawal of extracellular signaling factors, oxidative and osmotic stress, irradiation and the treatment of cells with chemotherapeutic drugs and ischemic shock (44). The flavonoid, honokiol, has been shown to exert a protective effect against antimycin A (an inhibitor of mitochondrial electron transport)-induced oxidative cell damage via the activation of PI3K and/or AKT in MC3T3-E1 osteoblastic cells (45). In the present study, CZE also induced the activation of PI3K, AKT1 and AKT3, which was inhibited by dRib (Fig. 7). Since these signaling molecules are involved in cellular survival pathways, CZE may be cytoprotective for osteoblastic cells during oxidative stress responses.

Excess ROS must be promptly eliminated from the cells by a variety of antioxidant defense mechanisms. Cellular antioxidant enzymes and other redox molecules serve to counterbalance ROS generated in cells. Superoxide dismutase (SOD), which catalyzes the dismutation of the superoxide anion into hydrogen peroxide and molecular oxygen, is one of the most important antioxidant enzymes (46). SOD enzymes are classified into 3 groups: CuZn-SOD (SOD1) is located in the cytoplasm, Mn-SOD (SOD2) in the mitochondria and EC-SOD (SOD3) is extracellular. Glutathione peroxidase (GPx) catalyzes the reduction of hydroperoxides, including hydrogen peroxides, by reduced glutathione and functions to protect the cell from oxidative damage. GPx1 is the most abundant version, found in the cytoplasm of almost all mammalian tissues, whose preferred substrate is hydrogen peroxide. GPx4 has a high preference for lipid hydroperoxides. It has been reported that various flavonoids increase the activity of antioxidant enzymes in osteoblastic cells. Quercetin can diminish oxidative human osteoblastic cell damage by scavenging the radicals and by upregulating the expression of heme oxygenase-1 (HO-1) and SOD1 exposed to cigarette smoke medium (47). An extract of total flavonoids from persimmon leaves has been shown to significantly decrease the level of ROS and malondialdehyde (MDA), while increasing the activity of catalase (CAT), SOD and GPx in MC3T3-E1 cells (48). Simvastatin has been shown to abate oxidative stress by enhancing catalase, HO-1 and SOD activity and suppressing NADPH oxidase activity in an aged and ovariectomized rat model (49). Another study demonstrated that intracellular redox imbalance caused by SOD1 deficiency plays a pivotal role in the development and progression of bone fragility both in vivo and in vitro (51). In this study, in addition to the biochemical aspects of oxidative stress, the gene expression of antioxidative enzymes was investigated. The reducing sugar, dRib, exerted a profound inhibitory effect on the gene expression of SOD1, SOD2, SOD3, GPx1 and GPx4. However, when the osteoblastic were treated with CZE in the presence of $20 \mathrm{mM} \mathrm{dRib}$, a significant increase in the gene expression levels of SOD2, SOD3 and GPx4, but not SOD1 and GPx1 was observed (Fig. 8).

In conclusion, in the present study, we demonstrate that CZE attenuates dRib-induced cell damage in MC3T3-E1 osteoblastic cells due to its antioxidant activity and postive 
effect on differentiation, which may promote bone recovery in diabetes-associated bone diseases.

\section{Acknowledgements}

This study was supported by 'Industrialization Propulsion Unit for Chrysanthemum and Abalone', Wando-gun, Jeollanam-do, Republic of Korea.

\section{References}

1. Collins RA, Ng TB, Fong WP, Wan CC and Yeung HW: A comparison of human immunodeficiency virus type 1 inhibition by partially purified aqueous extracts of Chinese medicinal herbs. Life Sci 60: PL345-PL351, 1997.

2. Hu CQ, Chen K, Shi Q, Kilkuskie RE, Cheng YC and Lee KH: Anti-AIDS agents, 10. Acacetin-7-O-beta-D-galactopyranoside, an anti-HIV principle from Chrysanthemum morifolium and a structure-activity correlation with some related flavonoids. J Nat Prod 57: 42-51, 1994.

3. Sassi AB, Harzallah-Skhiri F, Bourgougnon N, Aouni M: Antimicrobial activities of four Tunisian Chrysanthemum species. Indian J Med Res 127: 183-192, 2008.

4. Liu Q, Liu H, Yuan Z, Wei D and Ye Y: Evaluation of antioxidant activity of chrysanthemum extracts and tea beverages by gold nanoparticles-based assay. Colloids Surf B Biointerfaces 92: 348-352, 2012.

5. He J, Chen F, Chen S, Lv G, Deng Y, Fang W, Liu Z, Guan Z and $\mathrm{He} \mathrm{C}$ : Chrysanthemum leaf epidermal surface morphology and antioxidant and defense enzyme activity in response to aphid infestation. J Plant Physiol 168: 687-693, 2011.

6. Marongiu B, Piras A, Porcedda S, Tuveri E, Laconi S, Deidda D and Maxia A: Chemical and biological comparisons on supercritical extracts of Tanacetum cinerariifolium (Trevir) Sch. Bip. with three related species of chrysanthemums of Sardinia (Italy). Nat Prod Res 23: 190-199, 2009.

7. Wu TY, Khor TO, Saw CL, Loh SC, Chen AI, Lim SS, Park JH, Cai L and Kong AN: Anti-inflammatory/anti-oxidative stress activities and differential regulation of Nrf2-mediated genes by non-polar fractions of tea Chrysanthemum zawadskii and licorice Glycyrrhiza uralensis. AAPS J 13: 1-13, 2011.

8. Seo JY, Lim SS, Park J, Lim JS, Kim HJ, Kang HJ, Yoon Park JH and Kim JS: Protection by Chrysanthemum zawadskii extract from liver damage of mice caused by carbon tetrachloride is maybe mediated by modulation of QR activity. Nutr Res Pract 4 : 93-98, 2010.

9. Robertson RP, Harmon J, Tran PO, Tanaka Y and Takahashi H: Glucose toxicity in beta-cells: type 2 diabetes, good radicals gone bad, and the glutathione connection. Diabetes 52: 581-587, 2003.

10. Robertson RP: Chronic oxidative stress as a central mechanism for glucose toxicity in pancreatic islet beta cells in diabetes. J Biol Chem 279: 42351-42354, 2004.

11. López-Ibarra PJ, Pastor MM, Escobar-Jiménez F, Pardo MD, González AG, Luna JD, Requena ME and Diosdado MA: Bone mineral density at time of clinical diagnosis of adult-onset type 1 diabetes mellitus. Endocr Pract 7: 346-351, 2001.

12. Tuominen JT, Impivaara O, Puukka P and Ronnemaa T: Bone mineral density in patients with type 1 and type 2 diabetes. Diabetes Care 22: 1196-1200, 1999.

13. Herskind AM, Christensen K, Nørgaard-Andersen K and Andersen JF: Diabetes mellitus and healing of closed fractures. Diabete Metab 18: 63-64, 1992.

14. Bai XC, Lu D, Bai J, Zheng H, Ke ZY, Li XM and Luo SQ Oxidative stress inhibits osteoblastic differentiation of bone cells by ERK and NF-kappaB. Biochem Biophys Res Commun 314: 197-207, 2004

15. Fatokun AA, Stone TW and Smith RA: Hydrogen peroxideinduced oxidative stress in MC3T3-E1 cells: The effects of glutamate and protection by purines. Bone 39: 542-551, 2006.

16. Seeman E: Reduced bone formation and increased bone resorption: rational targets for the treatment of osteoporosis. Osteoporos Int 14 (Suppl 3): S2-S8, 2003.

17. Thornalley P, Wolff S, Crabbe $J$ and Stern A: The autoxidation of glyceraldehyde and other simple monosaccharides under physiological conditions catalysed by buffer ions. Biochim Biophys Acta 797: 276-287, 1984.
18. Kaneto H, Fujii J, Myint T, Miyazawa N, Islam KN, Kawasaki Y, Suzuki K, Nakamura M, Tatsumi H, Yamasaki Y and Taniguchi N: Reducing sugars trigger oxidative modification and apoptosis in pancreatic beta-cells by provoking oxidative stress through the glycation reaction. Biochem J 320: 855-863, 1996.

19. Bunn HF and Higgins PJ: Reaction of monosaccharides with proteins: possible evolutionary significance. Science 213: 222-224, 1981.

20. Koh G, Suh KS, Chon S, Oh S, Woo JT, Kim SW, Kim JW and Kim YS: Elevated cAMP level attenuates 2-deoxy-Dribose-induced oxidative damage in pancreatic beta-cells. Arch Biochem Biophys 438: 70-79, 2005.

21. Koh G, Lee DH and Woo JT: 2-Deoxy-D-ribose induces cellular damage by increasing oxidative stress and protein glycation in a pancreatic beta-cell line. Metabolism 59: 325-332, 2010.

22. Lee YJ, Suh KS, Choi MC, Chon S, Oh S, Woo JT, Kim SW, Kim JW and Kim YS: Kaempferol protects HIT-T15 pancreatic beta cells from 2-deoxy-D-ribose-induced oxidative damage. Phytother Res 24: 419-423, 2010.

23. Suh KS, Oh S, Woo JT, Kim SW, Kim JW, Kim YS and Chon S: Apigenin attenuates 2-deoxy-D-ribose-induced oxidative cell damage in HIT-T15 pancreatic $\beta$-cells. Biol Pharm Bull 35: 121-216, 2012.

24. Choi EM and Kim YH: Hesperetin attenuates the highly reducing sugar-triggered inhibition of osteoblast differentiation. Cell Biol Toxicol 24: 225-231, 2008.

25. Lee KH and Choi EM: Myricetin, a naturally occurring flavonoid, prevents 2-deoxy-D-ribose induced dysfunction and oxidative damage in osteoblastic MC3T3-E1 cells. Eur J Pharmacol 591: $1-6,2008$

26. Suh KS, Choi EM, Kwon M, Chon S, Oh S, Woo JT, Kim SW, Kim JW and Kim YS: Kaempferol attenuates 2-deoxy-D-riboseinduced oxidative cell damage in MC3T3-E1 osteoblastic cells. Biol Pharm Bull 32: 746-749, 2009.

27. Kanno S, Anuradha CD and Hirano S: Localization of zinc after in vitro mineralization in osteoblastic cells. Biol Trace Elem Res 83: 39-47, 2001.

28. Suh KS, Chon S, Oh S, Kim SW, Kim JW, Kim YS and Woo JT: Prooxidative effects of green tea polyphenol (-)-epigallocatechin-3-gallate on the HIT-T15 pancreatic beta cell line. Cell Biol Toxicol 26: 189-199, 2010.

29. Balint E, Szabo P, Marshall CF and Sprague SM: Glucoseinduced inhibition of in vitro bone mineralization. Bone 28: 21-28, 2001.

30. Terada M, Inaba M, Yano Y, Hasuma T, Nishizawa Y, Morii H and Otani S: Growth-inhibitory effect of a high glucose concentration on osteoblast-like cells. Bone 22: 17-23, 1998.

31. Han SH, Sung KH, Yim DS, Lee SK, Lee CK, Ha NJ and Kim KJ: The effect of linarin on LPS-induced cytokine production and nitric oxide inhibition in murine macrophages cell line RAW264.7. Arch Pharm Res 25: 170-177, 2002.

32. Clifford MN, Wu W, Kirkpatrick J and Kuhnert N: Profiling the chlorogenic acids and other caffeic acid derivatives of herbal chrysanthemum by LC-MS ${ }^{\mathrm{n}}$. J Agric Food Chem 55: 929-936, 2007.

33. Lin LZ and Harnly JM: Identification of the phenolic components of chrysanthemum flower (Chrysanthemum morifolium Ramat). Food Chem 120: 319-326, 2010.

34. Sudo H, Kodama HA, Amagai Y, Yamamoto S and Kasai S: In vitro differentiation and calcification in a new clonal osteogenic cell line derived from newborn mouse calvaria. J Cell Biol 96: 191-198, 1983.

35. Bellows CG, Aubin JE, Heersche JN: Initiation and progression of mineralization of bone nodules formed in vitro: the role of alkaline phosphatase and organic phosphate. Bone Miner 14: 27-40, 1991.

36. Domon S, Shimokawa H, Yamaguchi S and Soma K: Temporal and spatial mRNA expression of bone sialoprotein and type I collagen during rodent tooth movement. Eur J Orthod 23: 339-348, 2001.

37. Chen Y, Bal BS and Gorski JP: Calcium and collagen binding properties of osteopontin, bone sialoprotein, and bone acidic glycoprotein-75 from bone. J Biol Chem 267: 24871-24878, 1992.

38. Khosla S: Minireview: the OPG/RANKL/RANK system. Endocrinology 142: 5050-5055, 2001.

39. Yang L, Takai H, Utsunomiya T, Li X, Li Z, Wang Z, Wang S, Sasaki Y, Yamamoto H and Ogata Y: Kaempferol stimulates bone sialoprotein gene transcription and new bone formation. J Cell Biochem 110: 1342-1355, 2010. 
40. Takuwa Y, Ohse C, Wang EA, Wozney JM and Yamashita K: Bone morphogenetic protein-2 stimulates alkaline phosphatase activity and collagen synthesis in cultured osteoblastic cells, MC3T3-E1. Biochem Biophys Res Commun 174: 96-101, 1991.

41. Nakase T, Takaoka K, Masuhara K, Shimizu K, Yoshikawa $H$ and Ochi T: Interleukin-1 $\beta$ enhances and tumor necrosis factor- $\alpha$ inhibits bone morphogenetic protein-2-induced alkaline phosphatase activity in MC3T3-E1 osteoblastic cells. Bone 21: 17-21, 1997.

42. Vivanco I and Sawyers CL: The phosphatidylinositol 3-kinase AKT pathway in human cancer. Nat Rev Cancer 2: 489-501, 2002.

43. Yao R and Cooper GM: Requirement for phosphatidylinositol-3 kinase in the prevention of apoptosis by nerve growth factor. Science 267: 2003-2006, 1995.

44. Franke TF, Kaplan DR and Cantley LC: PI3K: Downstream AKTion blocks apoptosis. Cell 88: 435-437, 1997.

45. Choi EM: Honokiol protects osteoblastic MC3T3-E1 cells against antimycin A-induced cytotoxicity. Inflamm Res 60: 1005-1012, 2011.

46. Zelko IN, Mariani TJ and Folz RJ: Superoxide dismutase multigene family: a comparison of the CuZn-SOD (SOD1), Mn-SOD (SOD2), and EC-SOD (SOD3) gene structures, evolution, and expression. Free Radic Biol Med 33: 337-349, 2002.
47. Braun KF, Ehnert S, Freude T,Egaña JT, Schenck TL, Buchholz A, Schmitt A, Siebenlist S, Schyschka L, Neumaier M, Stöckle U and Nussler AK: Quercetin protects primary human osteoblasts exposed to cigarette smoke through activation of the antioxidative enzymes HO-1 and SOD-1. ScientificWorldJournal 11: 2348-2357, 2011.

48. Sun L, Zhang J, Lu X, Zhang L and Zhang Y: Evaluation to the antioxidant activity of total flavonoids extract from persimmon (Diospyros kaki L.) leaves. Food Chem Toxicol 49: 2689-2696, 2011.

49. Yin H, Shi ZG, Yu YS, Hu J, Wang R, Luan ZP and Guo DH: Protection against osteoporosis by statins is linked to a reduction of oxidative stress and restoration of nitric oxide formation in aged and ovariectomized rats. Eur J Pharmacol 674: 200-206, 2012.

50. Nojiri H, Saita Y, Morikawa D, Kobayashi K, Tsuda C, Miyazaki T, Saito M, Marumo K, Yonezawa I, Kaneko K, Shirasawa T and Shimizu T: Cytoplasmic superoxide causes bone fragility owing to low-turnover osteoporosis and impaired collagen cross-linking. J Bone Miner Res 26: 2682-2694, 2011. 